Aletria, Belo Horizonte, v. 28, n. 4, p. 87-101, 2018

\title{
Representatividade e empoderamento nas narrativas de escravidão: da literatura à série televisiva
}

\section{Representation and Empowerment in Slave Narratives: From Literature to TV Series}

\author{
Isabella Santos Mundim \\ Instituto Federal de Brasília (IFB), Brasília, Distrito Federal / Brasil \\ isabsm@globo.com
}

Resumo: Este trabalho investiga como criadores pertencentes a grupos minoritários traduzem experiências de subjugação e violência em narrativas de representatividade e empoderamento. $\mathrm{O}$ foco são duas narrativas de escravidão lançadas em 2016 - o romance The Underground Railroad, de Colson Whitehead, e a série televisiva Underground, de Misha Green e Joe Pokaski - que se propõem o desafio de reelaborar criticamente o passado. Nelas, Whitehead e a dupla Green e Pokaski lembram o que a América esqueceu, retratam a experiência da servidão do ponto de vista de quem a viveu e a experiência do senhor branco do ponto de vista de quem ele escravizou. Nessa perspectiva, The Underground Railroad e Underground superam o mero registro e apontam para acontecimentos e pessoas ausentes dos relatos dominantes. Para além disso, as duas narrativas inauguram espaços e tempos de resistência, já que que assumem o compromisso com a construção da memória dos Estados Unidos a partir do viés da margem e da exclusão.

Palavras-chave: Colson Whitehead; Misha Green; Joe Pokaski; narrativas de escravidão; série televisiva; resistência; empoderamento.

Abstract: We investigate how minority artists translate subjection and violence experiences into narratives of self-representation and empowerment. The focus are two slave narratives from 2016 - the novel The Underground Railroad, by Colson Whitehead and the TV series Underground, by Misha Green and Joe Pokaski - that propose a critical elaboration of the past. Whitehead and Green-Pokaski bring forth what America 
has apparently forgotten, and present slavery by narrating black experience from their point of view. The Underground Railroad and Underground rethink national history and present alternative versions to the dominant reports. Moving beyond the official version of events, both narratives create spaces and times of resistance, committed to underscoring the specific circumstances of enslaved women.

Keywords: Colson Whitehead; Misha Green; Joe Pokaski; slave narratives; television series; resistance; empowerment.

Como resgatar aquelas vidas indissociáveis e indistinguíveis das enunciações terríveis que as condenaram à morte, dos livros de contabilidade que as identificaram feito unidades de valor, dos contratos que as descreveram como propriedade, e das crônicas banais que as despiram de qualidades humanas? [...] Como atentar para os gemidos e choros, as canções indecifráveis, o crepitar do fogo nos canaviais, a lamentação por quem morreu, e os gritos de vitória, e traduzi-los todos em palavras?

Essa provocação, de autoria da especialista em história e literatura afro-americana Saidiya Hartman, expressa o sentimento que atormenta muitos dos interessados em escrever relatos sobre o comércio transatlântico de escravos africanos e a experiência subsequente da escravidão nas Américas. Hartman diagnostica que a dificuldade é de duas ordens: a primeira diz respeito à tarefa de se descrever o que se deu de forma fidedigna - sem isentar o homem branco da culpa e responsabilidade pelos crimes que praticou - face à escassez do arquivo histórico. A segunda, e igualmente significativa, reporta-se à tarefa de se descrever a enormidade da violência que a população escravizada sofreu sem reduzi-la a um conjunto de corpos alvo de genocídio. Do

\footnotetext{
1 " $[\mathrm{H}]$ ow does one recuperate lives entangled with and impossible to differentiate from the terrible utterances that condemned them to death, the account books that identified them as units of value, the invoices that claimed them as property, and the banal chronicles that stripped them of human features? [...] How does one listen for the groans and cries, the undecipherable songs, the crackle of fire in the cane fields, the laments for the dead, and the shouts of victory, and then assign words to all of it?" (HARTMAN. Venus in Two Acts, p. 3, tradução minha).
} 
contrário, arrisca-se cair na armadilha da reprodução indiscriminada da "gramática da violência", ${ }^{2}$ a despeito das boas intenções de quem se presta a suplementar as lacunas e os silêncios da narrativa eurocêntrica dominante.

Nesse sentido, um preceito importante há de orientar o trabalho tanto de pesquisadores quanto de ficcionistas. ${ }^{3}$ Toda vez que se pesquisa e publica sobre tráfico negreiro e/ou sobre escravidão negra africana, toda vez que se ficcionaliza tais temáticas, deve-se cuidar para a representação da condição de subjugação não implicar em privar o subjugado de sua humanidade e individualidade. Mesmo escravizado, esse sujeito personifica mais que as espoliações múltiplas que o atingem; para além delas, tem de se reservar espaço, na história e na ficção, para episódios de protagonismo seu, com foco em enfrentamento e retaliação, independente do sucesso ou do fracasso último dessa iniciativa de reagir.

Mesmo quando se atenta para tais questões e se zela pela abordagem ética, representar a violência que a escravidão promove e reproduz, traduzir a violação e destruição de corpos de que ela se alimenta, narrativizar a sujeição e resistência relativas à vida da pessoa escravizada é projeto estético e político dos mais espinhosos. De autobiógrafos a ficcionistas, de escultores a pintores e fotógrafos, de roteiristas e diretores de cinema a criadores de série televisiva, muitos tentaram - e tentam - levar adiante tal empreitada, com resultados que variam desde a apreciação sensível do tópico até o tratamento capaz de provocar indignação e repúdio.

$\mathrm{Na}$ América do Norte do século XIX, homens e mulheres que escapam do cativeiro são os primeiros a fazê-lo. ${ }^{4}$ Para tanto, produzem um tipo de texto intitulado slave narrative - ou narrativa de escravidão, e inauguram a tradição literária de autoria africana e afrodescendente no país. Logo, a exemplo de Frederick Douglass e Harriet Jacobs, autores de Narrative of the Life of Frederick Douglass, an American Slave, Written by Himself (1845) e Incidents in the Life of a Slave Girl, Written by Herself (1861), respectivamente, eles escrevem histórias verídicas, pródigas na descrição da violência sistêmica e sistemática, num exercício de narração

\footnotetext{
2 "How does one revisit the scene of subjection without replicating the grammar of violence?" (HARTMAN. Venus in Two Acts, p. 4, tradução minha).

${ }^{3}$ Cf. HARTMAN. Venus in Two Acts.

${ }^{4} \mathrm{Cf}$. GATES JR. Introduction.
} 
que "diz da luta do escravo negro para conquistar a liberdade e alfabetizarse, ao mesmo tempo em que denuncia 'a peculiar instituição' escravista". 5 Ademais, denúncia combina-se, à época, com ferramenta de militância efetiva, já que os abolicionistas se valem da publicação e circulação de tal literatura para angariar aliados para a causa antiescravagista.

$\mathrm{Na}$ América do Norte contemporânea, por sua vez, parte daqueles que se encarregam da tarefa de relatar os horrores do tráfico negreiro e da escravidão preferem realizá-la mediante a criação de narrativas ficcionais, consideradas arcabouço apropriado à dramatização da barbárie. ${ }^{6}$ Remanescentes das slave narratives de outrora, tais obras surgem no âmbito do movimento dos direitos civis das décadas de 50 e 60, associadas à mobilização organizada contra a segregação racial e à valorização do legado linguístico e sociocultural negro-africano. Ora com textos que imaginam a experiência da negritude e da servidão do ponto de vista de quem a viveu e a experiência do senhor branco do ponto de vista de quem ele escravizou, ora com textos que recuperam o passado escravista e o retratam "na qualidade de fenômeno histórico cujos sentidos e consequências se estendem até o presente", ${ }^{7}$ essa modalidade de ficção existe para cumprir o propósito, primeiro, de centralizar - e idealmente ressignificar-aqueles corpos explorados até e além do limite da aniquilação.

Dentre esses criadores, vale destacar o autor afrodescendente Colson Whitehead. Em 2016, ele é um dos que se propõe a dizer o indizível, e o diz efetivamente, quando resgata a jovem escrava Cora da invisibilidade e silêncio a que mulheres como ela são condenadas e a elege sua protagonista, em romance intitulado The Underground Railroad (Underground Railroad: os caminhos para a liberdade, na edição brasileira). Aqui, nos moldes das narrativas de escravidão de Douglass e Jacobs, que o leitor novecentista popularizou, Whitehead também traça um relato de atrocidades gratuitas e cotidianas, que a fuga de Cora

\footnotetext{
5 "[Each slave narrative] tells the story of a black slave's struggle for literacy and freedom, while testifying against the 'peculiar institution', which in practice meant human bondage and humiliation." (GATES JR. Introduction, p. ix, tradução minha).

${ }^{6}$ Cf. RUSHDY. Neo-Slave Narrative.

7 "The major characteristic of the neo-slave narrative is [...] the representation of chattelhood as a historical phenomenon that has lasting cultural meaning and enduring social consequences" (RUSHDY. Neo-Slave Narrative, p. 533, tradução minha).
} 
intenta interromper. E tudo isso ele executa sem poupar a sensibilidade do leitor médio, presumivelmente branco, e sem absolvê-lo da parcela de culpa histórica que lhe cabe.

Diferente de quem escreveu com o intuito primordial de converter leitores à causa abolicionista, diferente de quem teve de "adaptar as memórias da vida em cativeiro para fazê-las palatáveis aos aliados em potencial", diferente de quem teve de "silenciar acerca de muitas coisas e de "esquecer' várias outras", ${ }^{8}$ Whitehead escancara as violências, certas e terríveis, que a amnésia coletiva naturaliza; inscreve as violências que a sociedade da época (e de hoje) quer apagar. Em vez de biografia - fictícia - para fins de comoção e convencimento, focada no triunfo inevitável da narradora, tem-se assim uma narrativa que, se propicia Cora com vitórias discretas, mas significativas, também a situa em meio ao que Toni Morrison denomina "episódios demasiado horríveis de relatar".

Filha abandonada pela mãe quando esta empreende a fuga; criança condenada pelos donos à vida na companhia das mulheres da propriedade ditas loucas; jovem cujo corpo vira alvo de agressão sexual, Whitehead, todavia, confere a Cora subjetividade e complexidade psicológica suficientes para livrá-la da sina da mulher escravizada que figura, única e exclusivamente, enquanto locus de miséria e dor. Seja quando se dedica à criação de um pequeno jardim, seja quando intervém em defesa de uma criança cativa prestes a ser espancada, seja quando simula aquiescência a fim de criticar as relações de dominação, Cora vale-se de estratégias de resistência que lhe garantem existir para além da espetacularização do sofrimento negro.

The Underground Railroad deriva dessa tensão que Whitehead arquiteta entre sujeição e contestação, revés e êxito, ceticismo e esperança, sua expressividade e poder. Deriva da caracterização multifacetada da protagonista, cuja vida interior e atitude traduzem as tensões que embasam a trama. Isso se verifica, notadamente, por ocasião do que acontece na Carolina do Sul, primeiro local onde Cora se refugia depois de escapar da Geórgia, onde sempre vivera na companhia de um

\footnotetext{
8 "In shaping the experience to make it palatable to those who were in a position to alleviate it, they were silent about many things, and they "forgot' many other things" (MORRISON. The Site of Memory, p. 91, tradução minha).

9 "But let us drop a veil over these proceedings too terrible to relate" (MORRISON. The Site of Memory, p. 91, tradução minha).
} 
escravo letrado de nome Ceaser, um homem que a introduz à realidade de uma rede subterrânea de túneis, estações ferroviárias, trens e respectivos condutores. Ali, onde se detém por meses, Cora - e o leitor - desperta para o fato de que, não obstante as aparências, "a liberdade é sempre precária, a segurança é sempre provisória". ${ }^{10}$ Nesta parte da América em que ela vive por algum tempo, onde a autoridade estatal declara proteger seu bem-estar, o espectro da tortura e da servidão continua a atormentá-la.

Logo, ao mesmo tempo em que lhe ensinam as letras e a alfabetizam, submetem seu corpo - e de outros "diferentes" e "indesejáveis" - a toda sorte de exames e experimentos, na expectativa de incluí-los, todos, num programa de saúde pública de viés eugênico. Não se trata da única circunstância em que ameaçam ferir sua integridade física ou privá-la de autonomia. Num estado que é residência de gente "bondosa" e "acolhedora", violências afins a esperam.

Tal se dá, similarmente, quando a "premiam" com uma oferta de emprego: trabalhar no Museu das Maravilhas Naturais. No museu, Cora e mais homens e mulheres negras revezam-se na encenação de três cenas. Eles ora interpretam Scenes from Darkest Africa (Cenas da África Negra), ora interpretam Life on the Slave Ship (A Vida do Navio Negreiro), ora interpretam Typical Day on the Plantation (Um Dia Típico na Fazenda). Um espetáculo grotesco que os aprisiona num artifício que, se não os obriga a simular a agressão de que foram vítimas, faz coisa tão repugnante quanto: omite os crimes que o opressor perpetrou e perpetra, exime de culpa os que lucram com o empreendimento escravagista e ignora a devastação advinda da colonização de corpos alheios.

De resto, tal performance impugna a própria existência de Cora. Neste sentido, configura oportunidade ideal para Cora refutar, mesmo que só para si mesma, a veracidade de tal quadro.

$[N]$ inguém queria falar sobre a verdadeira situação do mundo. E ninguém queria ouvir. [...] Os brancos vieram para [esta] terra em busca de um recomeço e para fugir da tirania de seus senhores, exatamente como os homens livres haviam fugido dos seus. Mas os ideais que acalentavam para si eram negados aos outros. [...] [E]les tomavam o que pertencia a outras pessoas, independentemente de

10 "In The Underground Railroad, freedom is always precarious, safety merely temporary" (BENNETT. Ripping the Veil, tradução minha). 
ser algo que se podia segurar na mão, como a terra, ou não, como a liberdade. [...] Corpos roubados cultivando terra roubada. Era um motor que não parava, sua fornalha faminta alimentada com sangue. ${ }^{11}$

Aqui e noutros momentos, a experiência a autoriza para a crítica: ao contrário do curador ianque do museu que concebera a exposição, ela conhece o cenário que analisa; traz na pele um catálogo das agressões que sofreu e, na memória, um inventário dos ataques, alguns deles mortais, que presenciou. Pode dizer de quem são os corpos que alimentam o tabaco, de quem é o sangue que irriga o algodão. A esse ato de resistência silenciosa, segue um outro de natureza similar, que Cora leva adiante enquanto posa na vitrine e se oferece à apreciação dos visitantes:

Cora selecionava um cidadão por hora para afugentar com o olhar. [...] Ela distinguia na multidão os elos frágeis, aqueles que fraquejavam sob seu olhar. O elo frágil - ela gostava do som disso. Procurar a imperfeição na corrente que mantém uma pessoa em servidão. [...] As pessoas que ela escolhia, jovens e velhos, da parte rica da cidade ou das ruas mais modestas, não perseguiam apenas Cora. Como uma comunidade, eram manilhas. Se ela continuasse com aquilo, desbastando elos frágeis sempre que os encontrasse, talvez colaborasse em alguma coisa.

Ela ficou boa no seu olhar assustador. [...] As pessoas sempre cediam, surpresas com aquele ataque estranho [...] Era uma boa lição, pensou Cora, aprender que o escravo, o africano entre vocês, também está olhando para você. ${ }^{12}$

${ }^{11}$ WHITEHEAD. Undergound Railroad: os caminhos para a liberdade, p. 125. No original: "[...] nobody wanted to speak on the true disposition of the world. And no one wanted to hear it. [...] The whites came to this land for a fresh start and to scape the tyranny of their masters, just as the freemen had fled theirs. But the ideals they held up for themselves, they denied others. [...] [T] hey snatched away what belonged to other people, whether it was something you could hold in your hand, like dirt, or something you could not, like freedom. [...] Stolen bodies working stolen land. It was an engine that did not stop, its hungry boiler fed with blood" (WHITEHEAD. The Underground Railroad: A Novel, p. 116-117).

${ }^{12}$ WHITEHEAD. Undergound Railroad: os caminhos para a liberdade, p. 134-135. No original: "Cora selected one patron per hour to evil-eye. [...] She picked the weak links out from the crowd, the ones who broke under her gaze. The weak link - she liked the 
Tal prática, que Cora incorpora à sua rotina de trabalho no museu, traz à lembrança performances análogas, que o sujeito escravizado se vê na obrigação de realizar, sob pena de punição. ${ }^{13}$ Nas ocasiões em questão, o senhor de escravos divide com ele a cena: atua tal qual pessoa benevolente, que "recompensa" quem vive sob seu jugo com intervalos para descanso e entretenimento, além de "presenteá-lo", numa data ou noutra, com a "oportunidade ímpar" de integrar a atração que se apresenta na casa-grande. Esse exercício de reiterar atos (cantar e dançar à luz da fogueira, louvar antepassados e entidades deificadas, exibir-se para convidados) de acordo com o que as regras determinam, traz em si, a despeito de tudo, uma fagulha de antagonismo e obstinação. A depender das circunstâncias, "essas performances podem se voltar contra o que fora a sua presumível razão de ser, [...] explicitando o caráter artificial e repressivo próprio do contentamento advindo da subjugação [...] e articulando oportunidades de atuação previamente indisponíveis". ${ }^{14}$

Nessa aptidão que Cora dispõe para engendrar espaços de autonomia em meio à devastação e ao cativeiro, nessa conviç̧ão visceral que ela tem para si de que deve sobreviver a qualquer custo, nessa crença hesitante que ela experimenta quanto ao seu futuro e ao de outros, a protagonista de The Underground Railroad aproxima-se de outras personagens femininas, escravas fugitivas como ela, presentes noutra narrativa de escravidão da atualidade.

ring of it. To seek the imperfection in the chain that keeps you in bondage. [...] The people she chose, young and old, from the rich part of town or the more modest streets, did not individually persecute Cora. As a community, they were shackles. If she kept at it, chipping away at weak links wherever she found them, it might add up to something. / She got good at her evil eye. [...] They always broke, the people, not expecting this weird attack. [...] It was a fine lesson, Cora thought, to learn that the slave, the African in your midst, is looking at you too" (WHITEHEAD. The Underground Railroad: A Novel, p. 125-126).

${ }^{13}$ Cf. HARTMAN. Scenes of Subjection: Terror, Slavery, and Self-Making in Nineteenth-Century America.

14 “ $[\ldots]$ these performances were sometimes turned against their instrumental aims, [...] indicating the repressive construction of contented subjection [...] and creat[ing] a space for action not generally available" (HARTMAN. Scenes of Subjection: Terror, Slavery, and Self-Making in Nineteenth-Century America, p. 8, tradução minha). 
Tal narrativa é Underground ${ }^{15}$ série televisiva criada pela dupla Misha Green e Joe Pokaski. Curiosamente, trata-se de outro texto que traz, no título, referência explícita à rede clandestina de rotas de fuga e esconderijos denominada Underground Railroad (literalmente, ferrovia subterrânea), e pela qual escaparam, estima-se, cerca de 100.000 escravos. ${ }^{16}$ Dela participavam brancos e negros, homens e mulheres, gente livre e ex-escravos, militância que inclui os que financiam a empreitada, os que concedem passagem, os que lideram fuga, os que abrigam fugitivos e os que os acolhem nos Estados Livres. Essa rede, que Whitehead literaliza numa malha ferroviária subterrânea, a televisão dramatiza numa representação próxima do que de fato existiu, a começar pela música tema da série, Heaven's Door. À imagem e semelhança de cantigas da época, cujas letras constituem códigos que se prestavam à decifração, essa música serve de "carta de navegação" lírica para as personagens que fogem, com palavras que camuflam referências específicas, indicativas de pontos no mapa que designam local de parada ou de encontro seguros.

Logo durante a primeira temporada, a narrativa centraliza um grupo de escravos ("the Macon 7", ou "os sete cativos da fazenda Macon"), que, tal qual várias pessoas reais antes dele, arrisca uma fuga em direção ao Norte. Rosalee, a heroína da série, filha mestiça do proprietário da fazenda de algodão e da escrava encarregada de gerenciar a casa-grande, faz parte desse grupo. Inicialmente temerosa, relutante em abandonar a mãe e os irmãos, ela ainda assim auxilia os futuros fugitivos nos preparativos. Às vésperas da fuga, entretanto, depois de declarar que permanecerá na casa-grande, ela é alvo da agressão do capataz. Ele tenta estuprá-la e ela retalia: naquele instante, certa de que o feriu fatalmente e de que a condenarão de forma sumária, só lhe resta fugir. Daí em diante, a cada episódio, Rosalee e os outros avançam em meio a toda sorte de crise, seja uma natureza inclemente que lhes dificulta o progresso, um corpo que ameaça cair em colapso ou um caçador de recompensas que segue, inabalável, em seu encalço.

\footnotetext{
${ }^{15}$ Underground estreou em março de 2016 no canal de TV a cabo WGN America. Desta data até quando se decidiu pelo seu cancelamento, em maio de 2017, a série contou com duas temporadas e 20 episódios.

${ }^{16}$ Cf. BORDEWICH. Bound for Canaan: The Underground Railroad and the War for the Soul of America.
} 
Esta fórmula, que alicerça a trama principal, resulta então numa narrativa capaz de alternar momentos de ação e de quietude, de violência e de ternura, de derrota e de vitória, de denúncia e de reconciliação. Ao longo das dezenas de horas que compõem a série, enfatiza-se, sim, a rotina de crueldades típica da vida da pessoa escravizada, ratifica-se o caráter criminoso da sua condição, condena-se aqueles cúmplices de um sistema baseado na pilhagem da vida, da liberdade e do trabalho alheios. Underground, porém, diferentemente das narrativas que priorizam a vitimização do escravo e privam-no da possibilidade de agência, imagina uma ficção histórica onde o sujeito negro resiste face à opressão; onde eles e elas agem, defendem-se, rebelam-se, e até vingam-se.

O material promocional atesta este impulso criativo, o desejo de, nas palavras da cocriadora e produtora afro-americana Misha Green, "retratar esse período com foco em pessoas escravizadas que exercitam autonomia. [...] Afinal, uma série que versa sobre a Underground Railroad destaca, necessariamente, aqueles esperançosos, com ânsia de lutar, que ousam se rebelar". ${ }^{17}$ Em conformidade, o lema da primeira temporada é "Break free" (Liberte-se). Já o pôster que estampa Rosalee traz a declaração "I will break free" (Me libertarei), enquanto os pôsteres ilustrativos das demais personagens, especialmente dos que planejam fugir, incluem assertivas de cunho idêntico, a saber, "I have the plan" (Sou capaz de planejar a fuga), "I will take what I am owed" (Conquistarei o que me devem), "I have the tools" (Possuo as habilidades necessárias), "I will find the courage" (Serei corajoso), "I have faith" (Tenho fé na empreitada) e "I will do whatever it takes" (Farei o que for preciso). Ademais, a conclusão da temporada reitera a mensagem, mas a expande e a ressignifica também. Rosalee, depois de superar todos os obstáculos que se interpõem entre ela e a liberdade, diz o seguinte, em depoimento ao abolicionista William Still: ${ }^{18}$

17 "You've never seen this time period portrayed with those who are enslaved having personal agency. [...] [A] show about the Underground Railroad naturally focuses on those with hope, those with a will to fight, those who took a chance to rebel" (LOGAN. Underground Isn't Afraid To Challenge What a TV Show About Slavery Should Be Like, tradução minha).

${ }^{18}$ William Still é homem negro livre cujo sucesso se estende a diversas arenas, entre elas, o empreendedorismo, o ativismo e a filantropia. Sobre seu ativismo, interessa destacar, em especial, sua participação na Underground Railroad que atravessava o estado da Pensilvânia. Além de colaborar no planejamento e execução de ações de 
$\mathrm{Na}$ fazenda eu vivia assustada. Sem tempo para sentir qualquer coisa além de medo. Você só se preocupava em manter a cabeça baixa. "Sim, senhor". Desviar o olhar. Suportar o que fosse... Mas cada ofensa, cada insulto, cada vez que me chamavam de "menina" de um jeito que me fez odiar a palavra, toda aquela raiva à flor da pele, prestes a explodir. Tudo isso não ficou para trás. Não consigo mais ignorar o que vejo ao meu redor. E se eu ficar aqui para começar uma nova vida é isso que estarei fazendo. Eu vou voltar para libertá-los! ${ }^{19}$

Ela cumpre a promessa. Após os créditos, em cena que anuncia o que está por vir, o espectador assiste Rosalee encontrar Harriet Tubman, vulgo "Moses" (Moisés), militante abolicionista que teve papel determinante na libertação de mais de 300 escravos. Nascida sob o jugo dos grilhões, Harriet conquista sua liberdade já adulta, em fuga solitária, depois de uma primeira tentativa frustrada na companhia de dois irmãos. Talvez a integrante/colaboradora feminina mais famosa da Underground Railroad, ela assegura seu lugar na história nos meses e anos subsequentes, quando retorna, por 13 vezes, aos Estados Escravistas, à frente de grupos armados que levam a cabo missões de resgate. ${ }^{20}$

resgate, Still, ao longo dos anos, também abriga centenas de fugitivos em sua residência, a quem entrevista, e cujas respostas ele transcreve para a posteridade. Tais depoimentos, em conjunto com biografias e relatos dos que escapam, integram depois volume de valor inestimável, intitulado The Underground Railroad. A Record of Facts, Authentic Narratives, Letters, \& C., Narrating the Hardships, Hair-Breadth Escapes and Death Struggles of the Slaves in their Efforts for Freedom, as Related by Themselves and Others, or Witnessed by the Author; Together with Sketches of Some of the Largest Stockholders, and Most Liberal Aiders and Advisers, of the Road (1872). Cf. BORDEWICH. Bound for Canaan: The Underground Railroad and the War for the Soul of America.

19 'Back on the plantation, I was so scared. Wasn't no time to feel nothin' else. You just had to keep your head down. 'Yes, massa.' Look away. Bear it. But every slight, every insult, every time they used that word 'girl' in a way that made me hate the word, all that anger just waitin' below the surface. All that [ain't] behind [me]. I can't look away no more. And if I stay up here and try to start a new life, that's all I'm gonna be doin'. I'm goin' back" (THE WHITE whale, tradução minha).

${ }^{20} \mathrm{Cf}$. BORDEWICH. Bound for Canaan: The Underground Railroad and the War for the Soul of America. 
No universo da série, essa mulher, que tanto arriscou e sacrificou em prol das causas em que acreditava, igualmente cumpre função de destaque. Na segunda temporada, que foi ao ar em 2017, Harriet é quem educa Rosalee nas táticas de resgate e confronto, é quem serve de mentora a Rosalee, com quem Harriet atua em parceria no presente da narrativa. Mais importante, ela, tanto quanto Rosalee (e os demais escravos que sobrevivem à fuga), é a personificação do lema dessa segunda temporada: "Rise up" (Rebele-se). Numa América às vésperas da Guerra Civil (1861-1865), Harriet é uma, dentre várias personagens, que antecipa a participação no conflito, insurgindo-se contra o aparato repressivo do Estado e combatendo quem age em nome dele, mediante palavras e ações. Isso se torna especialmente evidente no sexto episódio da temporada, intitulado "Minty".

Nele, a dupla Green e Pokaski dedica o episódio inteiro à presença e fala de Harriet Tubman. Durante mais de 50 minutos, a câmera enquadra o seu corpo à exceção de quase qualquer outro; mira nela, que domina o palco improvisado de onde discursa, de onde revive episódios de seu passado e exorta sua plateia à ação. Em meio aos seus pares, este corpo, negro, feminino, objeto de pilhagem, alvo de violências mil, se transforma - transcende a precariedade de suas origens para encarnar a promessa, moralmente irrecusável, de luta. As palavras finais traduzem tal demanda, a que as pessoas de bem, de ontem e de hoje, devem responder.

Não se negocia liberdade. [...] Não há acordo ou meia medida que resolva qualquer coisa, não para quem vive em cativeiro. E nem para nenhum de nós. Porque um país que levantaram com base na destruição de corpos sempre vai precisar de mais deles para a matança. Enquanto a escravidão existir, nenhum de nós, não importa quem, homem ou mulher, estará livre. [...] E se você não é capaz de pegar em armas contra essa injustiça, então você tem de atuar de alguma outra maneira. E você tem de agir com convicção. Deus proverá, mas você tem de fazer a sua parte. Você tem de decidir como vai lutar, que tipo de soldado vai ser. Como vai reagir contra aqueles que querem reviver os "bons e velhos tempos", que querem destruir tudo que há de correto no mundo. Não podemos ser complacentes em tempos de guerra. Isto significaria rendição. Significaria 
sacrificarmos nosso futuro e nossas almas. Ninguém pode isentar-se de participar, entenderam? ${ }^{21}$

Estas palavras, Harriet as pronuncia fitando o espectador. Ela o interpela diretamente, provoca-o, desafia-o; convoca-o para agir em solidariedade com os ativistas, os insurgentes, os perturbadores da ordem. Na América da série e na América da atualidade, ela alerta: alegar ignorância, deixar-se paralisar pela apatia equivalem, necessária e indiscutivelmente, à conivência com o sistema e as instituições racistas. Afinal, a violência que sustenta a nação escravocrata, tão flagrantemente exibida por ocasião do "açoitamento das costas", o "acorrentamento dos membros", o "estrangulamento de dissidentes", a "destruição de famílias", o "estupro de mães" e a "venda de crianças", ${ }^{22}$ é prenúncio da violência atual de que a população negra continua alvo. Pessoas cujos corpos carregam as marcas indeléveis da escravidão, elas seguem ameaçadas, encarceradas e assassinadas em números desproporcionais, a despeito da igualdade de oportunidades que o governo prometera.

Nesse sentido, Underground e The Underground Railroad, na mesma medida, respondem a estímulos tanto de então quanto de agora. Apontam para o que fingiram esquecer, para o que lograram escamotear e, ao fazê-lo, recuperam, em meio às ruínas do que foi, algo que atravessa séculos, em vigor no presente. Na América onde "é tradição destruir o

21 “There ain't no negotiations on freedom. [...] There ain't no compromises or no half measures that mean anything, not to those in bondage. And not for any of us either. 'Cause a country built on bodies will always need more for the slaughter. As long as slavery stands, ain't none of us, no matter hue, man or woman, be free. [...] [I]f you don't have it in you to take up arms against the injustice, then you got to pray another prayer. And you got to walk in it with conviction. He will provide, but you got to do your part. You got to find what it means for you to be a soldier. Beat back those that are tryin' to kill everything good and right in the world, and call it makin' it great again. We can't afford to be just citizens in a time of war. That'd be surrender. That'd be givin' up our future and our souls. Ain't nobody get to sit this one out, you hear me?" (MINTY, tradução minha).

${ }^{22}$ COATES. Entre o mundo e eu, p. 19-20. No original: "[...] the elevation of the belief in being white was $[\ldots]$ achieved through $[\ldots]$ the flaying of backs; the chaining of limbs; the strangling of dissidents; the destruction of families; the rape of mothers; the sale of children [...]" (COATES. Between the World and Me, p. 6). 
corpo negro", ${ }^{23}$ onde o destroem rotineiramente em defesa dum sonho de nação e civilidade, imaginar narrativas, literárias ou audiovisuais, que retratam a negritude no viés de quem habitou e habita um corpo negro significa, em última análise, iluminar o passado e confrontar o presente dum modo que faz jus à memória de quem a violência aniquila e de quem lhe resiste, além de assegurar-lhes a sobrevivência para além da morte e da destruição.

\section{Referências}

BENNETT, Brit. Ripping the Veil. New Republic, Washington, New York, 2 Aug. 2016. Disponível em: <https://newrepublic.com/article/135708/ colson-whiteheads-fantastic-voyage $>$. Acesso em: 25 jun. 2018.

BORDEWICH, Fergus M. Bound for Canaan: The Underground Railroad and the War for the Soul of America. New York: Harper Collins, 2005.

COATES, Ta-Nehisi. Between the World and Me. New York: Spiegel \& Grau, 2015.

COATES, Ta-Nehisi. Entre o mundo e eu. Tradução de Paulo Geiger. Rio de Janeiro: Objetiva, 2015.

GATES JR., Henry Louis. Introduction. In: GATES JR., Henry Louis (Ed.). The Classic Slave Narratives. New York: Mentor, 1997. p. ix-xviii.

HARTMAN, Saidiya V. Scenes of Subjection: Terror, Slavery, and SelfMaking in Nineteenth-Century America. New York: Oxford University Press, 1997.

HARTMAN, Saidiya V. Venus in Two Acts. Small Axe, Durham, NC, v. 12, n. 2, p. 1-14, 2008. doi: https://doi.org/10.1215/-12-2-1

LOGAN, Elizabeth. Underground Isn't Afraid To Challenge What a TV Show About Slavery Should Be Like. IndieWire, 18 Apr. 2016. Disponível em: <http://www.indiewire.com/2016/04/underground-isnt-afraid-tochallenge-what-a-tv-show-about-slavery-should-be-like-289780/>. Acesso em: 25 jun. 2018.

${ }^{23}$ COATES. Entre o mundo e eu, p. 107. No original: "In America, it is traditional to destroy the black body [...]" (COATES. Between the World and Me, p. 103). 
MINTY. Direction: Anthony Hemingway. In: UNDERGROUND. Creation: Misha Green, Joe Pokaski. Production: W. Mark McNair. [S.1.]: Get Lifted Film Company, Safehouse Pictures, Sony Pictures Television, 2016-2017. Vídeo, streaming (54 min.), widescreen, color., legend. Série exibida pela Amazon Prime. Season 2, episde 6.

MORRISON, Toni. The Site of Memory. In: ZINSSER, William (Ed.). Inventing the Truth: The Art and Craft of Memoir. Boston, New York: Houghton Mifflin, 1995. p. 83-102.

RUSHDY, Ashraf H. A. Neo-Slave Narrative. In: ANDREWS, William L.; FOSTER, Francis Smith; HARRIS, Trudier (Ed.). The Oxford Companion to African American Literature. New York: Oxford University Press, 1997. p. 533-535.

THE WHITE whale. Direction: Tim Hunter. In: UNDERGROUND. Creation: Misha Green, Joe Pokaski. Production: W. Mark McNair. [S.1.]: Get Lifted Film Company, Safehouse Pictures, Sony Pictures Television, 2016-2017. Vídeo, streaming (45 min.), widescreen, color., legend. Série exibida pela Amazon Prime. Season 1, episode 10.

UNDERGROUND. Creation: Misha Green, Joe Pokaski. Production: W. Mark McNair. [S.1.]: Get Lifted Film Company, Safehouse Pictures, Sony Pictures Television, 2016-2017. Vídeo, streaming (860 min.), widescreen, color., legend. Série exibida pela Amazon Prime.

WHITEHEAD, Colson. The Underground Railroad: A Novel. New York: Doubleday, 2016.

WHITEHEAD, Colson. Undergound Railroad: os caminhos para a liberdade. Tradução de Caroline Chang. Rio de Janeiro: Harper Collins, 2017.

Recebido em: 27 de junho de 2018. Aprovado em: 23 de outubro de 2018. 
